\title{
Impact of Covid-19 Outbreak on Hospital Based Cancer Registry in a Tertiary Care Hospital in South Tamilnadu
}

Section: Healthcare

ISI Impact Factor (2020-21): 1.899

IC Value (2020): 91.47 SJIF (2020) $=7.893$

\author{
Shantaraman $\mathrm{K}^{1}$, Chandhru Mari $\mathrm{R}^{\mathbf{2}^{*}}$, Johnsy Merla $\mathrm{J}^{3}$
}

Vice-Principal, Tirunelveli Medical College, Tirunelveli, Tamil Nadu, India; ${ }^{2}$ Assistant Professor of Pathology, Thiyagarajana Garpalayam Kottai,

Tamil Nadu, India; ${ }^{3}$ Associate Professor, Tirunelveli Medical College, Tirunelveli, Tamil Nadu, India.

(c) (i) (3)

Copyright@IJCRR

ABSTRACT

Introduction: Covid 19 pandemic has affected the delivery of health care particularly cancer care services throughout the world. Excess health care services were used to manage this pandemic and its complications. So, the shift in health care caused gaps in cancer screening services and treatment which got reflected in the fall of cancer entries in hospital based cancer registry(HBCR).

Methods: Tirunelveli hospital based cancer registry data were collected from the year 2016 to 2020 . The entries made during the year 2016 -2019 were tabulated. For the pandemic year 2020, cancer case incidence at various sites for each month are collected and tabulated and the fall in total cancer cases were analysed

Results: There is steady increase in total cancer cases entry in HBCR from 2016 - 2019. There is decreased total cancer case entries during the pandemic year 2020 compared to previous years from 2016-2019. In April - July 2020, during the peak of pandemic there is low cancer case entries in HBCR. This reflects there is shift in health care services delivery towards control and treatment of pandemic cases rather than to cancer care services.

Conclusion: The impact of Covid 19 pandemic on cancer cases in the tertiary care hospital in south Tamilnadu has resulted in decrease and delay in identifying new cancer cases and treatment delivery. These problems if unsolved will result in increased cancer burden and mortality for the upcoming years.

Key Words: Cancer screening, Covid 19 pandemic, Health care services, Hospital based cancer registry, Cancer Incidence, South Tamilnadu

\section{INTRODUCTION}

The major cause of mortality and morbidity in both developed and developing countries is Cancer. Globally cancer is the second leading cause of death, being responsible for an estimated 9.6 million annual deaths in $2018^{1}$ and about 50,000 new patients are diagnosed and require treatment every day. ${ }^{2}$ The estimated cancer case prevalence over 5 years in India is to be around 2.3 million with new cases of about 1.2 million and 0.69 million people dying because of it. ${ }^{3}$ Thus there is a need of an active cancer case surveillance for which "Cancer Registry" was identified. Cancer registry captures a complete summary of the patient's epidemiological data, history, clinical and pathological diagnosis, and outcome if any. ${ }^{4}$ But for the year 2020 an unpredicted worldwide occurrence of the coronavirus SARS-CoV-2 (COVID-19) pandemic which is not like any other seasonal infection ${ }^{5}$ and having a profound effect on the entire oncology community.
There is a heavy impact on patients, with reduced healthcare activities who often require frequent visits and extensive utilization of the health care system to manage their disease and treatment complications for a duration that cannot be accurately estimated. ${ }^{6,7}$

Due to delayed cancer diagnosis, and interruption of treatment necessitated by severe acute respiratory syndrome (SARS) CoV-2 infection precautions most of the population faces an increased sufferings from cancer related symptoms. ${ }^{8-11}$ Short term adjustments has been accommodated by many healthcare providers such as temporarily discontinuing non-emergent cancer screenings, shifting the delivery of care to tele health, delaying surgeries and other in-office cancer services to reduce transmission risk. ${ }^{12,13}$ The oncology patients have faced increased difficulty for acquiring their routine treatment since the health care services has been diverted mainly to prevent and control this deadly pandemic. ${ }^{14-16}$

\section{Corresponding Author:}

Chandhru Mari R, Assistant Professor of Pathology, Thiyagarajana Garpalayam Kottai, Tamil Nadu, India. Phone: 8220725753; Email: chandhrumari1@gmail.com.

ISSN: $2231-2196$ (Print)

Received: 21.12 .2021
ISSN: 0975-5241 (Online)

Revised: 09.01 .2022
Accepted: 23.01 .2022
Published: 01.03 .2022 
In this study, the incidence of cancer for the past four years from 2016 to 2019 data were collected from Hospital based cancer registry in Tirunelveli medical college, a tertiary care hospital in south Tamilnadu and compared with the covid -19 outbreak year 2020 .

\section{MATERIALS AND METHODS}

The institute ethical committee permission was obtained, Ethical clearance reference no: 1865/PATHO/2021 and the data were collected. Tirunelveli hospital based cancer registry data were collected from the year 2016 to 2020. The patients data were collected in a pre-structural format with all relevant history, diagnosis and treatment given. The data reported here also includes patients from nearby four districts - Tenkasi, Thoothukudi, Kanniyakumari, Virudhunagar. The entries made during the year 2016-2019 were tabulated and compared with the data during the year 2020. For the pandemic year 2020 cancer case incidence at various sites for each month are collected and tabulated.

\section{RESULTS}

The incidence of cancer in Tirunelveli medical college gradually rises from $2016(12.18 \%)$ to $2017(12.9 \%)$ and there is a rapid rise in $2018(15.1 \%)$ and $2019(17.1 \%)$. There is a sudden fall in the year 2020 with incidence of cancer being only $10.3 \%$ and the total number of cancer cases reported were only 560 cases. Also, on an average there is increased incidence of cancer in women compared to men. The incidence of cancer were analysed according to age. In males, the mean age from year 2016-2019 was 55 to 57 years and year 2020 shows a decrease in mean age which is around 53 years. Similarly, in females, the mean age was 52.8 in 2016, 56.2 in 2017, 53.3 in 2018, 54.4 in 2019 and year 2020 shows a decrease in mean age which was around 50.6 years (Table 1).

Table 2, Table 3 and Table 4 gives the incidence of cancer at various sites from the year 2016 to 2020 . Table 5 and 6 gives the top 5 leading sites of cancer from the year 2016 to 2020 . In 2016 the first leading site of cancer was from head and neck $(20.8 \%)$, followed by cancers in Female Genital tract (18.1\%), Gastrointestinal tract (15.1\%), Breast (14.7\%) and Thyroid (6.3\%). In 2017 the first leading site of cancer was from Breast $(21.1 \%)$, followed by cancers in head and neck (16.6\%), Female Genital tract (16.3\%), Gastrointestinal tract $(15.3 \%)$ and Bone and soft tissue tumours $(6.5 \%)$.

In 2018 the first leading site of cancer was from Breast (20.8\%), followed by cancers in head and neck (18.1\%), Gastrointestinal tract (15.1\%), Female Genital tract (14.7\%), and Bone and soft tissue tumours (6.3\%). In 2019 the first leading site of cancer was from head and neck $(20.1 \%)$, followed by cancers in Breast (16.8\%), Gastrointestinal tract (15.2\%), Female Genital tract (14.6\%), and Bone and soft tissue tumours $(7.9 \%)$.

In 2020 due to Covid 19 pandemic there is a steep fall in incidence of cancers in HBCR, total tumor cases reported being 560 cases. This was being $1 / 3$ rd of the cases reported compared to previous four years. Out of these 560 cases the leading site of cancer is Breast (20.1\%), followed by gastrointestinal tract (16.8\%), Head and neck (15.2\%), Female genital tract (14.6\%) and Lung (7.9\%).

Though the top five sites of cancer usually shared by Head and neck cancers, Breast cancers, FGT, GIT and Bone \& Soft tissue cancers, there is a steady rise in incidence of cancer cases in Bone and soft Tissue tumors, Lung and Haematopoietic cancers. The most common cancer in Head and neck was from Oral cavity and predominant of them being squamous cell carcinoma. The most common breast cancer being Invasive ductal carcinoma and the most common GIT cancer was from stomach predominant being Adenocarcinoma. The most common cancer in FGT being carcinoma cervix predominant being Squamous cell carcinoma non-keratinising type.

Table 6 and Chart 1 details about the monthly incidence of cancer at various sites for the year 2020. There was substantial decrease in cancer screenings, visits, therapy and surgeries with variations by cancer type and site during the months of this pandemic peak. At the peak of the pandemic during the months of April, May, June cancer case entries in HBCR is almost close to nil. Significant cancer services utilisation reductions were observed till the end of the covid-19 pandemic year 2020.

\section{DISCUSSION}

Cancer registrations are one of the important ingredients for cancer control and surveillance programme. The cancer registries provide details on burden and patterns of cancer in developing countries and helps in further research in etiology and prevention. There are two types of cancer registry a) Hospital based and b) Population based. HBCR plays an important role in assessing patients care, to participate in clinical research to evaluate therapy and to help plan hospital facilities. The population of the Tirunelveli district is 3077233 (2011 census data). Our hospital is the only tertiary medical care centre from the nearby districts and almost most of the cases around this territory are reported here except for few cases $^{17}$

In this study, there is a steady rise in head and neck cancers from 2017 to 2019 predominant being Oral cavity. Due to advance in diagnostic areas and proper follow up there is an 
early detection of many of the Breast \& Gastrointestinal tract cancers. Furthermore there is also steady rise in incidence of cancer cases from Male genital tract, Lung and Bone \& soft tissue tumors. Due to effective screening programmes there is an early detection of cancer cervix cases with a consistent rise of incidence from the year 2016 to 2019 . But this early screening programmes, advanced diagnostic methods and proper follow-up were severely affected by this pandemic situation resulting in decline in totally reported cancer cases.

Though Government of India and Tamilnadu restricted many non-essential activities, essential activities like health care and emergency services are in progress. Institutional health care providers have had greater reductions in delivery of cancer care, likely because of more limited supply of hospital resources caused by an influx of acutely ill covid-19 infected patients and patient reluctance to visit hospital outpatient clinics due to concerns regarding the risk of transmission of COVID-19. Notably, the considerable drops in cancer case entries in HBCR is not due to real decrease in cancer case incidence but due to various difficulties in conducting routine cancer screening programmes and oncology outpatient services. As a result of this patient's cancer treatment journey is extended and some may present with advanced stages. ${ }^{18}$

Moreover there is a heavy workload on healthcare providers during the pandemic with constant inflowing of covid-19 cases to our hospital and many of the health care providers and their families were themselves succumbed to this deadly pandemic. ${ }^{19}$ Behavioural interventions to encourage the timely symptomatic diagnosis of cancer are important. More public awareness campaigns should be created in educating early cancer care seeking is appreciable and numerous advertisements in social media stating the clinicians are in constant services in spite of the pandemic. Health care providers also should accept triage and risk stratification of patients with potentially serious disease and they should remember that the patients might already be in delayed presentation.

\section{CONCLUSION}

Cancer registry is backbone of cancer control. An error in the registration may lead to defect in assessment of cancer control. Cancer treatments are a priority in the healthcare system, but as health-care became increasingly occupied with caring for patients with COVID-19, these patients will inevitably take precedence. Patients needing immediate care are receiving treatment, but when possible, treatments will be delayed. Due to this disruption in cancer health care services most of the patients who will get benefitted by early simple treatment protocols may need much more complex and palliative treatment. ${ }^{20}$ When normal service resumes at a population and health-service level, there will be a huge backlog of patients with potential cancer symptoms needing urgent assessment. ${ }^{21,22}$ Cancer biomarkers and machine diagnostic approaches might support prioritisation of patients who are at great risk and providing immediate attention. The Great health care providers should accept the enhancing roles in providing proper cancer care health delivery.

So effective policies to promote cancer care and support the cancer ecosystem have the potential to reduce the expected morbidity and mortality in the population due to delayed cancer care by this deadly pandemic. Planning for recovery should commence as soon as possible.

\section{Acknowledgement: None}

\section{Source of funding: Self}

\section{Conflict of Interest: Nil}

\section{Authors' Contribution:}

\begin{tabular}{llll}
$\begin{array}{l}\text { S. } \\
\text { No }\end{array}$ & $\begin{array}{l}\text { Name of the } \\
\text { contributor }\end{array}$ & Role \\
\hline 1 & $\begin{array}{l}\text { Dr. R. Chandhru } \\
\text { Mari }\end{array}$ & $\begin{array}{l}\text { Correspond- } \\
\text { ing Author }\end{array}$ & Scientific content \\
2 & $\begin{array}{l}\text { Dr. K. Shantaraman } \\
\text { First Author }\end{array}$ & $\begin{array}{l}\text { Technical Support } \\
\text { Fechnical Support }\end{array}$ \\
\hline & Dr. JohnsyMerla & $\begin{array}{l}\text { Second } \\
\text { Author }\end{array}$ & Technich \\
\hline
\end{tabular}

\section{REFERENCES}

1. Bray F, Ferlay J, Soerjomataram I, Siegel RL, Torre LA, Jemal A. Global cancer statistics 2018: GLOBOCAN estimates of incidence and mortality worldwide for 36 cancers in 185 countries. Cancer J Clin. 2018;68:394-424.

2. Ward EM, Sherman RL, Henley SJ, Jemal A, Siegel DA, Feuer EJ. Annual report to the nation on the status of cancer, featuring cancer in men and women Age 20-49 years. J Nat Cancer Instit, 2019;111:1279-97

3. Mohandas KM, David G. The growing burden of cancer in India: epidemiology and social context: Lancet Oncol, May 2014.

4. Consolidated report of population based cancer based registries 2004-2006: National cancer Registry programme (ICMR), Bangalore 2009 .

5. Johnson HC, Gossner CM, Colzani E, Kinsman J, Alexakis L, Beauté J. Potential scenarios for the progression of COVID-19 epidemic in the European Union and the European Economic Area. Euro Surveill. 2020;25(9):2000202.

6. Bulki TK. Cancer Guidelines during the COVID-19 Pandemic. Lancet Oncol. 2020;21(5):629-30.

7. Liang W, Guan W, Chen R, Wang W, Li J, Xu K. Cancer patients in SARS-CoV-2 infection: a nationwide analysis in China. 2020;21:335- 336

8. Richards M, Anderson M, Carter P. The impact of the COVID-19 pandemic on cancer care. Nat cancer 1:565-567,2020

9. Kutikov A, Weinberg DS, Edelman MJ. A war on two fronts: Cancer care in the time of COVID-19. Ann intern Med 172:756758,2020

10. Sud A, Jones ME, Broggio J, Loveday C, Torr B, Garrett A, et al: Collateral damage: The impact on cancer outcomes of the COVID-19 pandemic. Annals of Oncology, Volume 31, Issue 8, p1065-1074. 
11. Schrag D, Hershman DL, Basch E: Oncology practice during the COVID-19 pandemic. May 2020;323920):2005-2006.

12. Anand S, Walling A, Wenger N. Impact of the COVID-19 pandemic on medical oncology utilization at a busy urban academic medical center. Clin Cancer Res 26, 2020.

13. Epstein MM, Sundaresan D, Fair M. Impact of COVID-19 on breast and prostate cancer screening and early detection in a large health care provider group. Clin Cancer Res 26, 2020.

14. Carethers JM, Sengupta R, Blakey R. Disparities in cancer prevention in the COVID-19 era. Cancer Prev Res (Phila)

15. Kaufman HW, Chen Z, Niles J. Changes in the number of US patients with newly identified cancer before and during the coronavirus disease 2019 (COVID-19) pandemic. JAMA Netw Open 3:e2017267,2020.

16. Fedewa SA, Yabroff KR, Zheng Z. Unemployment and cancer screening: Baseline estimates to inform health care provision in the context of COVID-19 economic distress. Clin Cancer Res 26,2020

17. National cancer registry programme consolidated report of hospital based cancer registries:2012-2014; National cancer Registry programme (ICMR), Bangalore 2016; p43-46.
18. World Health Organization. Rapid assessment of service delivery for NCDs

19. during COVID-19 pandemic. Geneva 2020

20. Fong D, Rauch S, Petter C, Haspinger E, Alber M, Mitterer M. Infection rate

21. and clinical management of cancer patients during the COVID-19 pandemic: experience from a tertiary care hospital in northern Italy. ESMO Open 2020;5: e000810.

22. van de Haar J, Hoes LR, Coles CE, Seamon K, Fröhling S, Jäger $\mathrm{D}$, et al. Caring for patients with cancer in the COVID-19 era. Nat Med 2020; 26: 665-71.doi: 10.1038/s41591-020-0874-8

23. Maringe C, Spicer J, Morris M. The impact of the COVID-19 pandemic on cancer deaths due to delays in diagnosis in England, UK: A national, population based modelling study. Lancet Oncol 21:1023-1034,2020.

24. Papautsky EL, Hamlish T: Patient-reported treatment delays in breast cancer care during the COVID-19 pandemic. Breast Cancer Res Treat 184:249-254, 2020.

Table 1: Lists out the yearly total confirmed cancer case incidence from 2016 -2020 in Hospital based cancer registry and gender distribution with mean age of incidence.

\begin{tabular}{lcccccccc} 
Year & Total Number of & \multicolumn{2}{c}{$\begin{array}{c}\text { Incidence } \\
\text { Biopsies }\end{array}$} & $\begin{array}{c}\text { Total Number of } \\
\text { Cancer }\end{array}$ & $\%$ & $\begin{array}{c}\text { Men } \\
\text { Women } \\
\%\end{array}$ & $\begin{array}{c}\text { Child } \\
\%\end{array}$ & $\begin{array}{c}\text { Mean Age } \\
\text { Women }\end{array}$ \\
\hline 2016 & 7528 & 917 & 12.18 & 45.03 & 54.19 & 0.70 & 57.4 & 52.8 \\
2017 & 8355 & 1084 & 12.9 & 46.3 & 53.1 & 0.6 & 55.3 & 56.2 \\
2018 & 7652 & 1156 & 15.1 & 40.1 & 57.9 & 1.0 & 56.4 & 53.3 \\
2019 & 8368 & 1429 & 17.1 & 48.4 & 53.2 & 0.4 & 57.4 & 54.4 \\
2020 & 5421 & 560 & 10.3 & 48.2 & 51.8 & 0 & 53.2 & 50.6 \\
\hline
\end{tabular}

Table 2: Total no. of cancer cases from year 2016 to 2020 at Head \& Neck, Breast and Thyroid.

\begin{tabular}{lccccc} 
Sites & $\mathbf{2 0 1 6}$ & $\mathbf{2 0 1 7}$ & $\mathbf{2 0 1 8}$ & $\mathbf{2 0 1 9}$ & $\mathbf{2 0 2 0}$ \\
Head and Neck & $\mathbf{2 6 3}$ & $\mathbf{1 8 0}$ & $\mathbf{2 1 0}$ & $\mathbf{2 8 8}$ & $\mathbf{7 2}$ \\
Oral Cavity & $\mathbf{1 2 9}$ & 101 & 112 & 174 & 32 \\
Larynx & 50 & 44 & 61 & 59 & 7 \\
Salivary Gland & 11 & 5 & 7 & 6 & 6 \\
Eye and Ear & 0 & 0 & 0 & 1 & 0 \\
Oropharynx & 29 & 19 & 24 & 22 & 8 \\
Nasopharynx & 16 & 5 & 1 & 4 & 2 \\
Hypopharynx & 28 & 6 & 5 & 22 & 6 \\
Breast & $\mathbf{1 0 6}$ & $\mathbf{2 2 9}$ & $\mathbf{2 4 1}$ & $\mathbf{2 4 1}$ & $\mathbf{1 1 0}$ \\
Thyroid & $\mathbf{4 4}$ & $\mathbf{5 2}$ & $\mathbf{5 0}$ & $\mathbf{5 4}$ & $\mathbf{2 5}$ \\
\hline
\end{tabular}

Table 3: Total no. of cancer cases from year 2016 to 2020 at FGT, MGT, and GIT

$\begin{array}{lccccc}\text { Sites } & \mathbf{2 0 1 6} & \mathbf{2 0 1 7} & \mathbf{2 0 1 8} & \mathbf{2 0 1 9} & \mathbf{2 0 2 0} \\ \text { Gastrointestinal tract (GIT) } & \mathbf{1 4 1} & \mathbf{1 6 6} & \mathbf{1 7 5} & \mathbf{2 1 8} & \mathbf{1 0 8} \\ \text { Esophagus } & 32 & 43 & 34 & 59 & 26 \\ \text { Stomach } & 62 & 50 & 73 & 82 & 50 \\ \text { Intestine } & 47 & 73 & 68 & 77 & 28\end{array}$


Table 3: (Continued)

\begin{tabular}{lccccc} 
Sites & $\mathbf{2 0 1 6}$ & $\mathbf{2 0 1 7}$ & $\mathbf{2 0 1 8}$ & $\mathbf{2 0 1 9}$ & $\mathbf{2 0 2 0}$ \\
Female Genital Tract (FGT) & $\mathbf{1 5 5}$ & $\mathbf{1 7 7}$ & $\mathbf{1 7 0}$ & $\mathbf{2 1 0}$ & $\mathbf{6 3}$ \\
Endometrium & 12 & 13 & 11 & 17 & 6 \\
Cervix & 109 & 104 & 101 & 116 & 33 \\
Ovary & 23 & 55 & 56 & 69 & 21 \\
Vagina & 4 & 4 & 1 & 4 & 2 \\
Vulva & 7 & 1 & 1 & 4 & 1 \\
Male Genital Tract (MGT) & $\mathbf{2 7}$ & $\mathbf{1 6}$ & $\mathbf{1 9}$ & $\mathbf{2 4}$ & $\mathbf{1 4}$ \\
Penis & 18 & 8 & 12 & 8 & 6 \\
Prostate & 6 & 6 & 3 & 10 & 3 \\
Testis & 3 & 2 & 4 & 6 & 5 \\
\hline
\end{tabular}

Table 4: Total no. of cancer cases from year 2016 to 2020 at Urinary tract and other sites.

\begin{tabular}{lccccc} 
Sites & 2016 & 2017 & 2018 & 2019 & 2020 \\
1. Urinary Tract & 37 & 23 & 27 & 26 & 11 \\
Kidney & 3 & 3 & 5 & 4 & 2 \\
Ureter & 0 & 0 & 1 & 0 & 0 \\
Bladder & 34 & 20 & 21 & 22 & 9 \\
2. Bone \& Soft tissue & 12 & 71 & 73 & 114 & 7 \\
3. Skin & 21 & 3 & 3 & 5 & - \\
4. Lymph node & 39 & 25 & 28 & 27 & 23 \\
5. Hematopoietic System & 29 & 32 & 39 & 50 & 30 \\
6. Lung & 9 & 71 & 72 & 99 & 36 \\
7. Heopatopancreatic and biliary & 7 & 16 & 18 & 25 & 14 \\
8. CNS & 12 & 7 & 7 & 8 & 5 \\
\hline
\end{tabular}

Table 5: Top 5 leading sites of cancer for the year 2016, 2017,2018,2019,2020

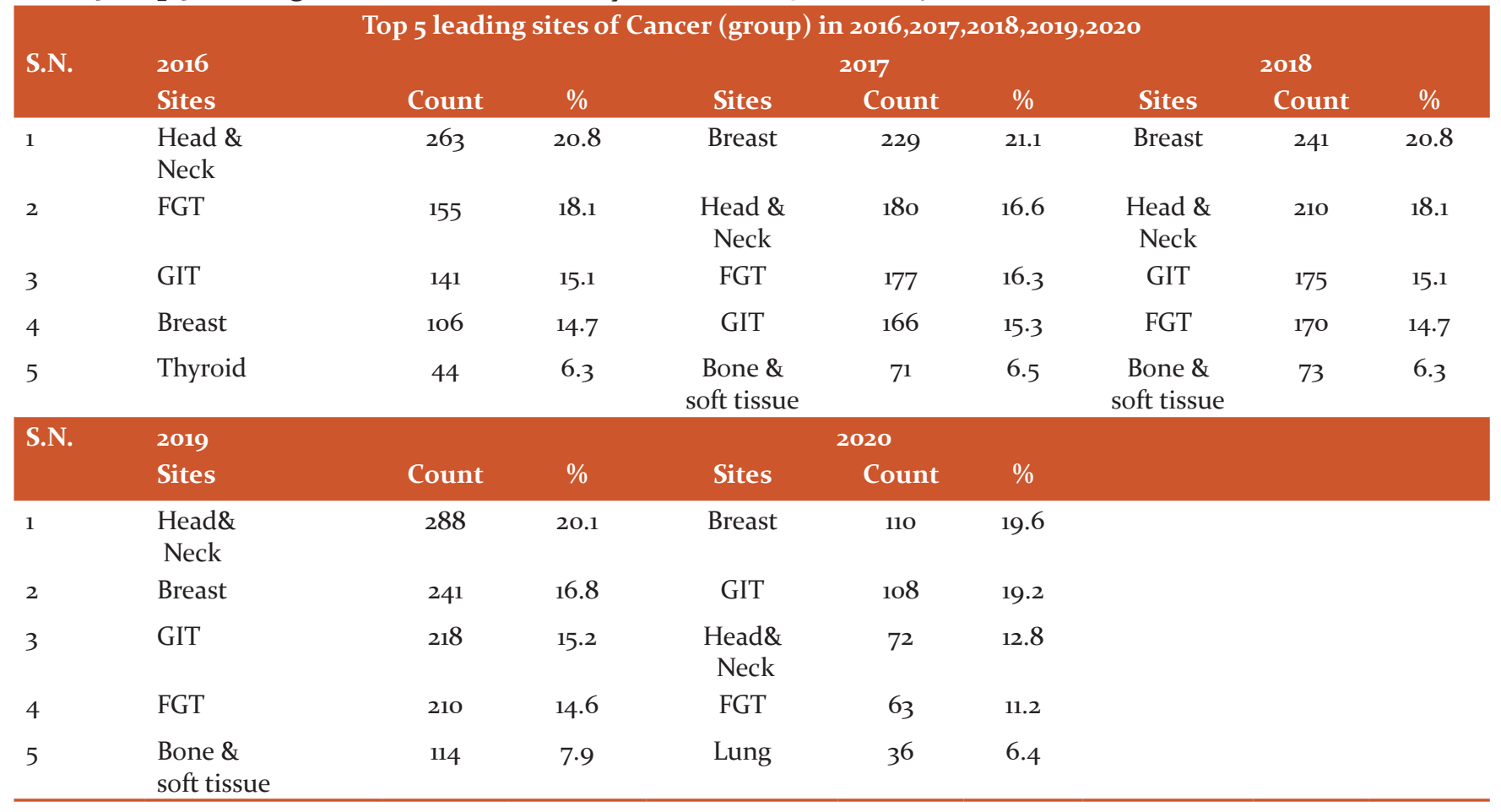


Table 6: Month wise cancer incidence for the pandemic year 2020

\begin{tabular}{lcccccccccccc}
\multicolumn{1}{c}{} & \multicolumn{1}{c}{ Month wise number of cancer case incidence } \\
SITES & Jan & Feb & Mar & Apr & May & Jun & Jul & Aug & Sep & Oct & Nov & Dec \\
Head \&Neck & 13 & 11 & 9 & 2 & 1 & 2 & 3 & 6 & 6 & 7 & 6 & 7 \\
Breast & 21 & 19 & 11 & 4 & 3 & 4 & 4 & 5 & 8 & 9 & 10 & 12 \\
Thyroid & 6 & 4 & 3 & - & - & - & 1 & 2 & 2 & 1 & 4 & 3 \\
GIT & 20 & 14 & 15 & 3 & 1 & 2 & 3 & 8 & 9 & 7 & 8 & 18 \\
FGT & 11 & 10 & 7 & 2 & 1 & 1 & 4 & 5 & 6 & 4 & 6 & 6 \\
MGT & 3 & 2 & 1 & - & - & 1 & 1 & - & 2 & 1 & 2 & 1 \\
Urinary tract & 3 & 3 & - & - & - & - & - & 1 & - & 1 & 1 & 2 \\
Bone, Soft tissue & 2 & 1 & - & - & - & - & 1 & 2 & - & - & 1 & - \\
Skin & - & - & - & - & - & - & - & - & - & - & - & - \\
Lymph node & 5 & 4 & 4 & - & - & - & 2 & 1 & 1 & 1 & 2 & 3 \\
Haematopoietic & 6 & 5 & 5 & - & - & - & 2 & 1 & 2 & 1 & 3 & 5 \\
Lung & 7 & 6 & 5 & - & - & - & 1 & 2 & 3 & 3 & 4 & 5 \\
Heopatopancreatic & 3 & 2 & 3 & - & - & - & - & 1 & 2 & 1 & 1 & 1 \\
CNS & 1 & - & 1 & - & - & - & 1 & - & - & 1 & - & 1 \\
\hline
\end{tabular}

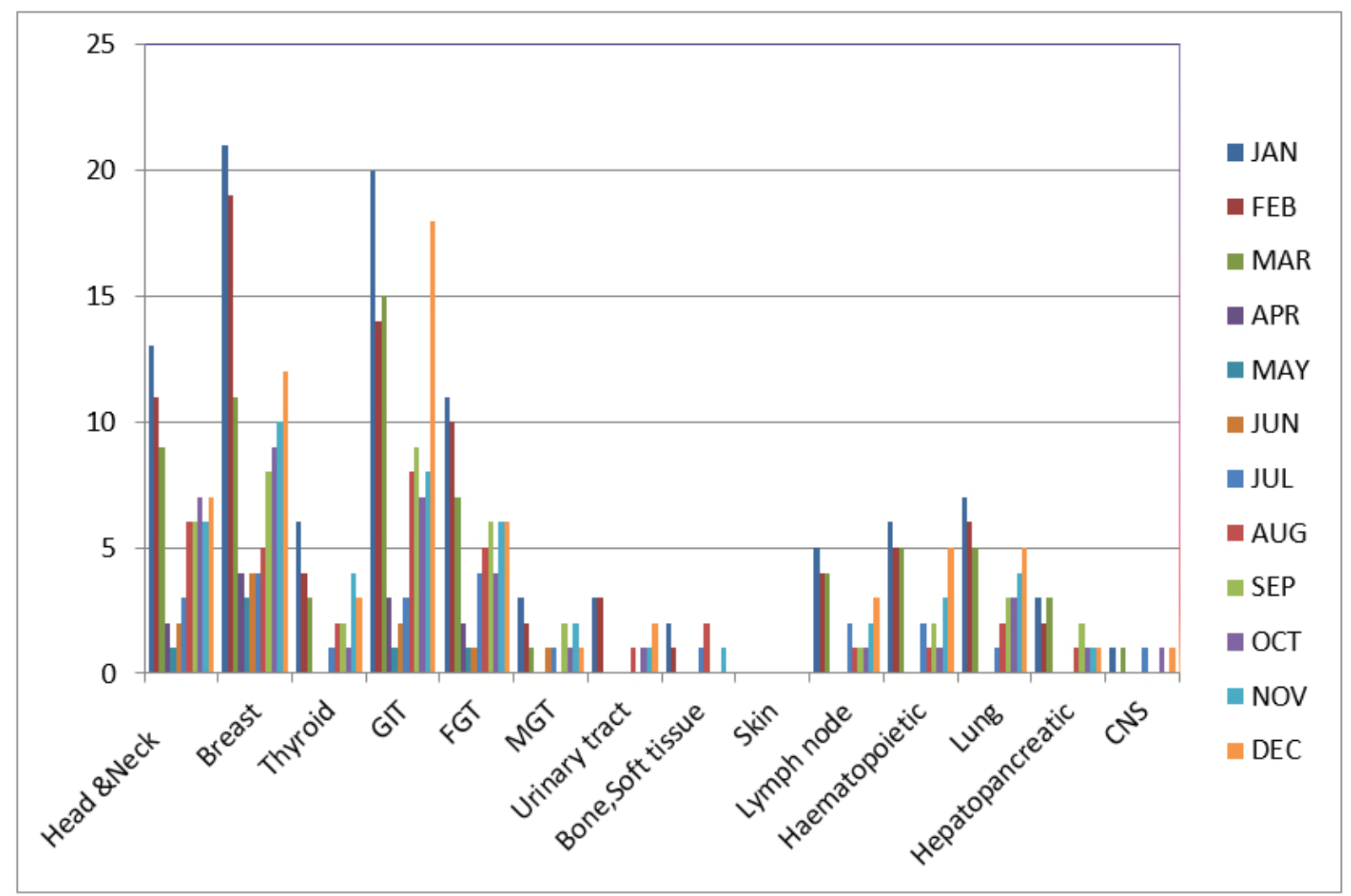

Chart 1: Monthwisecancer incidence for the pandemic year 2020 